\title{
Influence of Electrode Arrangement Method on Specific Energy Consumption and Productivity in Electrosynthesis of Fine Graphite Powder
}

\section{Andrei V. Kupriashov ( $\sim$ KupryashovAndrey@yandex.ru )}

Reshetnev Siberian State University of Science and Technology: Sibirskij gosudarstvennyj universitet nauki i tehnologij imeni akademika M F Resetneva https://orcid.org/0000-0003-1296-4942

\section{Ivan Y. Shestakov}

Reshetnev Siberian State University of Science and Technology: Sibirskij gosudarstvennyj universitet nauki i tehnologij imeni akademika M F Resetneva

\section{Research Article}

Keywords: Multifunctional coating, Fine graphite powder, Electrochemical action, Agglomeration, Sedimentation, Specific energy consumption

Posted Date: August 16th, 2021

DOI: https://doi.org/10.21203/rs.3.rs-817501/v1

License: (c) (1) This work is licensed under a Creative Commons Attribution 4.0 International License. Read Full License

Version of Record: A version of this preprint was published at The International Journal of Advanced Manufacturing Technology on January 27th, 2022. See the published version at https://doi.org/10.1007/s00170-021-08500-6. 


\section{INFLUENCE OF ELECTRODE ARRANGEMENT METHOD ON SPECIFIC ENERGY CONSUMPTION AND PRODUCTIVITY IN ELECTROSYNTHESIS OF FINE GRAPHITE POWDER}

\author{
Andrei V. Kupriashov' ${ }^{1}$ Ivan Y. Shestakov ${ }^{1}$ \\ ${ }^{1}$ Department of Electronic Engineering \\ and Telecommunications, Reshetnev \\ Siberian State University of Science and \\ Technology, Krasnoyarsk, 31, \\ Krasnoyarsky Rabochy Av., Russian \\ Federation
}

\section{KupryashovAndrey@yandex.ru • Yakovlevish@mail.ru}

\begin{abstract}
In this work, the influence of the location of the electrodes on the productivity of electrochemical process and specific energy consumption during direct current electrosynthesis of fine dispersed graphite powder is considered. The authors consider the possibility of using fine dispersed graphite powder obtained by electrolysis as the main component of a multifunctional aerospace coating. For this purpose, two types of devices was constructed: with a coaxial and parallel arrangement of the electrodes. The main elements of the device are a stainless steel cathode and a graphite anode immersed in electrolyte (an aqueous solution of salts). The authors consider the influence of the arrangement of the electrodes in the installation for direct current electrosynthesis from the point of view of the energy efficiency and productivity of electrochemical process. As a result of anodic oxidation, a fine powder from graphite of the MPG-6 brand was obtained. The size of the resulting graphite particles is 4-50 microns. This fine dispersed graphite powder can be used as the main component of a multifunctional coating in aircraft, since it has an even homogeneous structure, as well as higher values of the main mechanical properties of a multifunctional coating, which will lead to a decrease in the number of layers and the thickness of the
\end{abstract}

coating applied. The resulting graphite powder can also be used in the production of fireretardant and heat-insulating materials for the chemical, nuclear industry, instrumentation and heat power engineering.

Keywords Multifunctional coating - Fine graphite powder - Electrochemical action . Agglomeration · Sedimentation · Specific energy consumption

\section{Introduction}

A multifunctional coating is a multilayer structure applied on the surface of a product to protect it from external influence (pressure, temperature, corrosion, erosion, vibration) [13].

During operation, aircraft, in addition to force influences, are continuously exposed to an extensive complex of external physical influences of a heterogeneous type: ionizing and radio emissions, large differences in thermal disturbances, harmful effects of electrodynamic and gravitational fields, geomagnetic and ionospheric factors [4-7]. Therefore, the creation of an external multifunctional coating for the protection of rocket and space objects, which has a huge range of possibilities for reflection and absorption from external negative factors, is an urgent task in modern aerospace engineering.

In Aerospace Engineering, the main purpose of multifunctional coatings is thermal protection, protection against ionizing, electromagnetic and radio emission, reflection of laser influence, aimed at influencing the control system, electrical equipment and product devices. The secondary functions of multifunctional coating in rocket technology include increasing the strength and stiffness of individual external parts of the product, as well as protection against corrosion and erosion [8, 9].

\section{Description of the problem}

An important problem in the production of multifunctional coatings today is the heterogeneity of particles of the main 
component. The role of the shape and size of fillers for distribution and sedimentation in the polymer composite is very important for obtaining coatings with specified quality and functional characteristics [10-12]. The uniform distribution of filler particles in the polymer composite is determined by their tendency to agglomeration and sedimentation.

The influence of density and surface area of the filler particles has a significant effect on dispersion within the composite coating matrix.

It is known that the degree of aggregation and sedimentation of the polymer coating is always determined by the relative magnitude of the attractive forces of the filler particles $[13,14]$. The works indicate that the inhomogeneity of filler particles (graphite powder obtained by mechanical grinding) leads to a significant technological disadvantage - the production of coatings with a significantly increased density: instead of a given limit, the specific density value is significantly higher [15]. With a strictly specified coating thickness, this leads to a greater mass of sprayed coating layers, and, consequently, an excess mass of the manufactured product. There are several possible reasons for this problem: obtaining defects during production and disruption of the technological process during the manufacture of the filler [16], improper transportation conditions, and errors in mixing components, insufficient control during the formation of the polymer mixture of the composition.

Excess multifunctional coating is almost impossible to remove from the surface of the product without damage to the body [17]. Which leads to a number of problems: unnecessary costs for the removal of the aircraft, an increase in additional fuel volume, a decrease in the level of forecasting the behavior of the object in the atmosphere, a possible change in the trajectory of movement.

\section{Electrochemical method for producing graphite powder}

The above disadvantages can be partially eliminated by using a dispersed carbon filler [18] made on the basis of graphite with a hexagonal crystal structure as the main component of the coating.

Graphite powder was obtained by electrochemical method of - the anodic oxidation of high-strength fine-dispersed dense graphite of the MPG- 6 brand. Two main methods of producing graphite powder using a device with parallel and coaxial arrangement of electrodes are considered. Let's define the main advantages and disadvantages of both methods.

The main objective of the study is to establish the most advantageous method in terms of specific energy consumption, mass and size of the obtained particles.

The experiments were carried out under similar conditions: electrolytes of the same temperature range of $20-25{ }^{\circ} \mathrm{C}$; concentration and nature; electrolyte volume $\mathrm{Ve}=790 \mathrm{ml}$; equal value of DC voltage; processing time of 35 minutes; a constant voltage is applied to the electrodes after a single-half-period rectification with a voltage range of $2 \div 5 \mathrm{~V}$.

\subsection{Electrosynthesis of fine dispersed graphite powder by electrolysis with a coaxial arrangement of electrodes}

For the graphite powder production an electrolyzer was created, Fig. 1 shows its schematic diagram. The unit consists of a cylindrical fluoroplastic body (1), inside which the electrodes: cylindrical stainless steel cathode (2), anode - a graphite electrode of the MPG-6 brand (3) are placed. Between the electrodes there is a cylindrical plastic perforated container (4), the outer surface of which is covered with a dacron (5), which acts as a diaphragm. Current leads (7) and the anode (3) are installed on the plastic cover (6).

The method of producing a fine dispersed powder from graphite is based on the property of oxidized graphite to be dispersed during electrochemical oxidation [18]. Coaxially located electrodes: a stainless steel cathode on the periphery and an anode - a graphite electrode located in the center of the diaphragm electrolyzer. The electrolyte: a $15 \div 25 \%$ aqueous solution of soluble salts - is poured into a diaphragm electrolyzer. Voltage is applied to the electrodes after a single-halfperiod rectification, at an electric field strength 
of $40 \div 100 \mathrm{~V} / \mathrm{m}$ and an electric current of $100 \div 200 \mathrm{~mA}$.

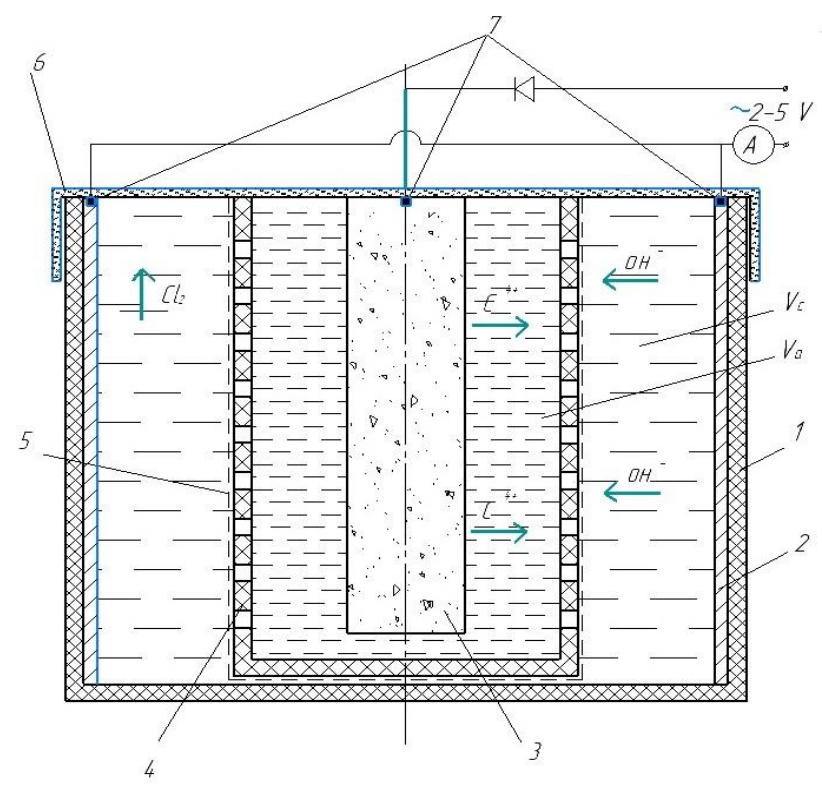

Fig. 1 Schematic diagram of the device:

1 - fluoroplastic device body; 2 - stainless steel cathode; 3 - graphite anode; 4 cylindrical perforated container; 5 - dacron diaphragm; 6 - plastic cover; 7 - current leads; $\mathrm{V}_{\mathrm{c}}$ - cathode space volume; $\mathrm{V}_{\mathrm{a}}$ - anode space volume

A diode is connected to the circuit in front of the anode, and an ammeter is connected to the circuit with the cathode to monitor the current value. When the electrodes are immersed in water and sufficient voltage is supplied to them, the process of electric current transfer starts by ions moving to the electrodes in the electrolyte and electrons in the external circuit. Positively charged ions migrate to the cathode, and negatively charged ions migrate to the anode under the influence of the electric field. The electron transition takes place on the electrodes. The cathode releases electrons into the solution and reduction processes occur in the near-electrode space. The processes of electron transfer from reacting particles to the electrode - oxidation takes place in the nearanode space.

The electric field strength of a system with coaxially arranged electrodes [19] is determined by:

$$
E=\frac{U}{r \times \ln \left(r_{1} / r_{0}\right)}
$$

where $r$ is the distance of a given point in the electrolyte, $r_{1}$ - distance from the center of the anode to the extreme surface of the cathode, $r_{0}$ is the radius of the anode.

The electrochemical process on electrodes in an aqueous solution of potassium chloride $(\mathrm{KCl})$ is considered.

Cathode reaction [20-22]:

$$
1 / 2 \mathrm{O}_{2}+\mathrm{H}_{2} \mathrm{O}+2 e^{-} \rightarrow 2(\mathrm{OH})^{-}
$$

Reaction at the anode [23, 24]:

$$
\begin{aligned}
& 2 \mathrm{Cl}^{-} \rightarrow 2 \mathrm{Cl}+2 e^{-} \\
& \mathrm{Cl}+\mathrm{Cl} \rightarrow \mathrm{Cl}_{2} \uparrow
\end{aligned}
$$

The total reaction:

$$
2 \mathrm{KCl}+1 / 2 \mathrm{O}_{2}+\mathrm{H}_{2} \mathrm{O} \rightarrow \mathrm{H}_{2} \uparrow+\mathrm{Cl}_{2} \uparrow+2 \mathrm{~K}+2(\mathrm{OH})^{-}
$$

When an electric current is passing through the anode, the $C^{4+}$ ion is formed from carbon atoms:

$$
C \rightarrow C^{4+}+4 e^{-}
$$

Further passage of an electric current through the system leads to the formation of molecular oxygen $\mathrm{O}_{2}$ from hydroxide ions in the near-anode space [25-26]:

$$
4 \mathrm{OH}^{-}-4 e^{-} \rightarrow \mathrm{O}_{2}+2 \mathrm{H}_{2} \mathrm{O}
$$

Molecular oxygen reacts with carbon ions $\mathrm{C}^{4+}$ to form carbon dioxide:

$$
\mathrm{C}^{4+}+4 e^{-}+\mathrm{O}_{2}+2 \mathrm{H}_{2} \mathrm{O} \rightarrow \mathrm{CO}_{2}+2 \mathrm{H}_{2} \mathrm{O}(8)
$$

The electrolyte is heated, the current increases, which indicates the heating of the aqueous solution - the graphite electrode begins to interact with oxygen and $\mathrm{CO}_{2}$ is 
released. That is, electrochemical oxidation proceeds to the tetravalent state of $\mathrm{CO}_{2}$ and a significant amount of oxygen is bound in an intermediate carbon compound in the general form [27]:

$$
\mathrm{C}_{x} \mathrm{~K}_{y}\left(\mathrm{H}_{2} \mathrm{O}\right)_{n},
$$

The values of $x, y, n$ depend on the oxidation state of carbon. $x$ for different compounds is 8 , $24,48,64$. The value of $y, n$ depends on the nature of the anion [28].

A hydrate shell is formed around $\mathrm{C}^{4+}$ ions. The hydrated ions formed stay in the water as a sediment [29-32]:

$$
\mathrm{C}^{4+}+2 \mathrm{H}_{2} \mathrm{O} \rightarrow \mathrm{C}\left(\mathrm{H}_{2} \mathrm{O}\right)_{2}
$$

After the end of the electrochemical process, solutions were obtained - anolyte and catholyte (Fig. 2). Due to the presence of suspended graphite particles, the anolyte has a darker color than the catholyte.

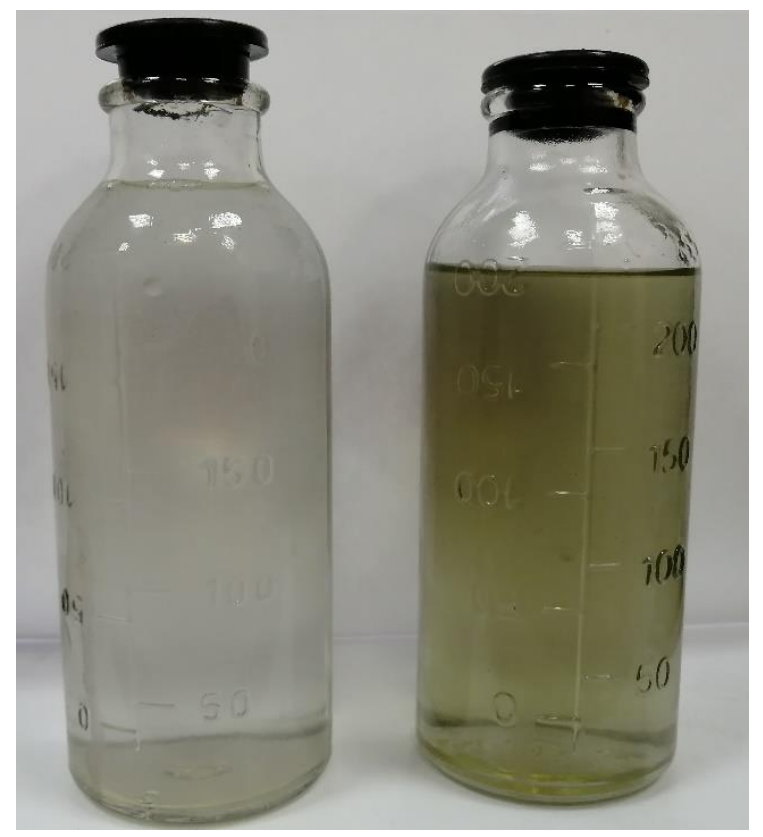

Fig. 2 Results of the electrochemical process flasks with catholyte (left) and anolyte (right)

Anolyte with graphite precipitate is passed through a special filtering device, the basis of which is a chemical conical funnel and several layers of filter paper, as a result, particles of fine graphite powder remain on the filter.
After washing with distilled water and drying, the finished product was obtained - fine graphite powder (Fig. 3).

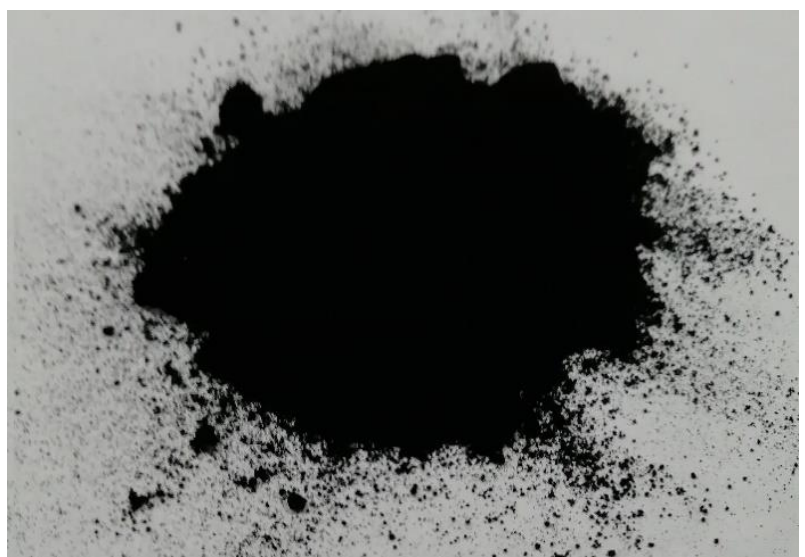

Fig. 3 The resulting product is a fine dispersed graphite powder

\subsection{Electrosynthesis of fine dispersed graphite powder by electrolysis with parallel arrangement of electrodes}

An electrolyzer with a parallel arrangement of electrodes is an open structure in which there is no separation by the diaphragm, and, consequently, there is no catholyte. Fig. 4 shows the design of a special electrochemical device consisting of an organic glass body (1), inside which the electrodes are placed: the cathode is a stainless steel plate (2), the anode is a graphite electrode of the MPG - 6 brand, plate shape (3). Between the electrodes is a working medium-a strong electrolyte: aqueous solutions of soluble salts. On the upper part of the electrodes there are current leads (4), which are connected to a direct current source through a diode.

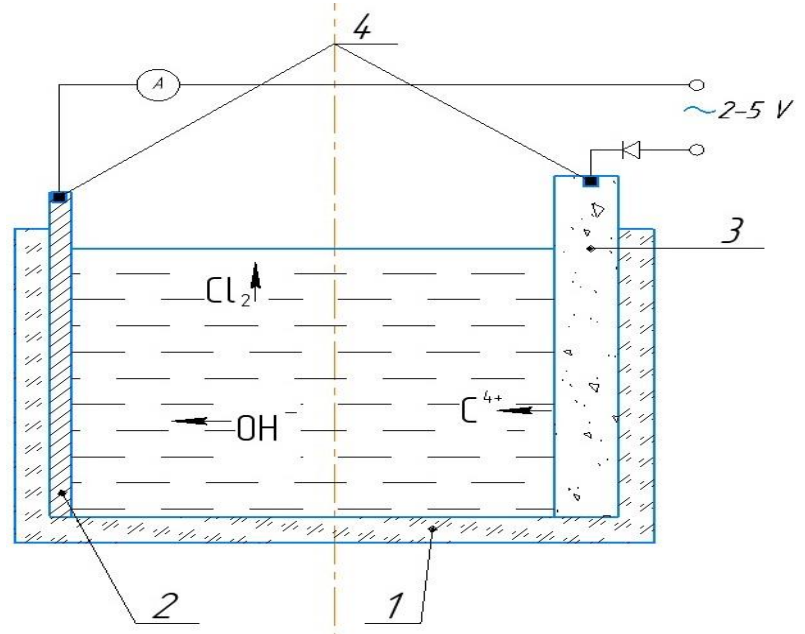


Fig. 4 Schematic diagram of a device with a coaxial arrangement of electrodes:

1 - device body; 2 - stainless steel cathode; 3 - graphite anode; 4 - - current leads

The electrolyte is a $15 \div 25 \%$ aqueous solution of soluble salts. Voltage is applied to the electrodes after a single-half-period rectification, at an electric field strength of $20 \div 60 \mathrm{~V} / \mathrm{m}$ and an electric current of $200 \div 900$ $\mathrm{mA}$.

The electrochemical process on electrodes in an aqueous solution of sodium chloride $(\mathrm{NaCl})$ is considered.

Cathode reaction [33]:

$$
2 \mathrm{H}_{2} \mathrm{O}+2 e^{-} \rightarrow \mathrm{H}_{2}+2(\mathrm{OH})^{-}
$$

The reaction at the anode is similar to that for the coaxial arrangement of the electrode $[34,35]$.

The total reaction:

$2 \mathrm{NaCl}+2 \mathrm{H}_{2} \mathrm{O} \rightarrow \mathrm{H}_{2} \uparrow+\mathrm{Cl}_{2} \uparrow+2 \mathrm{Na}+2(\mathrm{OH})^{-}$

As with the coaxial arrangement of the electrodes when an electric current is passing through the anode, the $\mathrm{C}^{4+}$ ion is formed from carbon atoms. Molecular oxygen reacts with carbon ions $\mathrm{C}^{4+}$ to form carbon dioxide:

$$
\mathrm{C}^{4+}+4 e^{-}+\mathrm{O}_{2}+2 \mathrm{H}_{2} \mathrm{O} \rightarrow \mathrm{CO}_{2}+2 \mathrm{H}_{2} \mathrm{O}(13)
$$

During the electrolysis process, the aqueous solution is heated and $\mathrm{C}^{4+}$ ions begin to interact with oxygen and $\mathrm{CO}_{2}$ is released. A significant amount of oxygen is bound in an intermediate carbon compound in the general form [36]:

$$
\mathrm{C}_{x} \mathrm{Na} a_{y}\left(\mathrm{H}_{2} \mathrm{O}\right)_{n},
$$

The values of $x, y, n$ depend on the oxidation state of carbon. $x$ for different compounds is 8 , $24,48,64$. The value of $y, n$ depends on the nature of the anion. According to the results of the analysis, the largest number of detected compounds is: $\mathrm{C}_{8} \mathrm{Na}_{4} \bullet\left(\mathrm{H}_{2} \mathrm{O}\right)_{2}$ and $\mathrm{C}_{24} \mathrm{Na}_{12} \bullet\left(\mathrm{H}_{2} \mathrm{O}\right)_{6}$ [37].
A hydrate shell is formed around $\mathrm{C}^{4+}$ ions. The hydrated ions formed stay in the water as a sediment.

After the end of the electrochemical process, an electrolyte with a sediment in the form of graphite powder was obtained (Fig. 5).

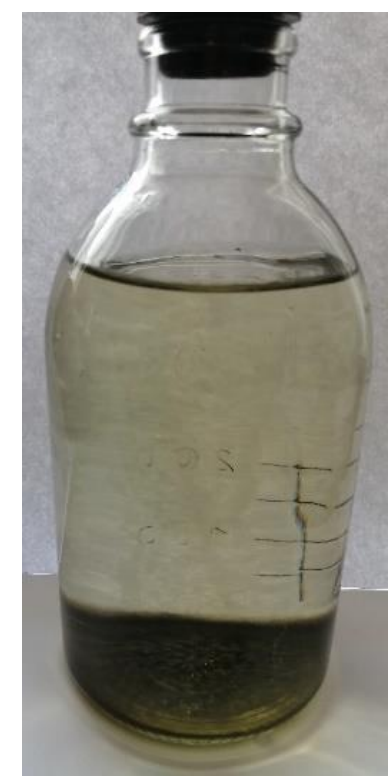

Fig. 5 The result of the experiment is a flask with an electrolyte

The further stages of obtaining graphite powder are similar to the methods of electrolysis with a coaxial arrangement of electrodes.

\section{Experimental results}

The graphite powder by the electrochemical method in two electrolyzers was examined with a digital microscope. The photo of the graphite powder obtained using a digital microscope is shown in Fig. 6. 


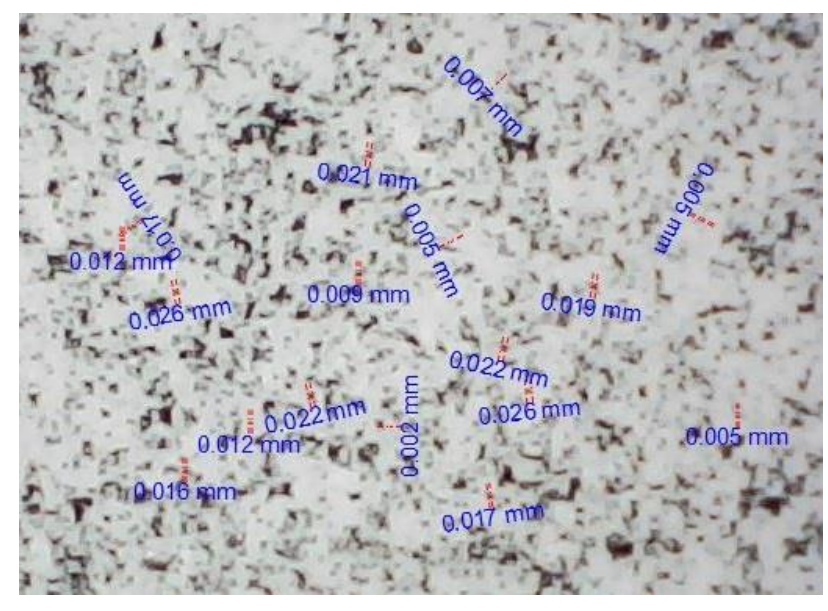

Fig. 6 A photograph of the graphite powder obtained during the experiment

Fig. 7 shows the image obtained with a video measuring device of the TESA-VISIO $300 G L$ laser principle with a magnification of up to $0.001 \mathrm{~mm}$.

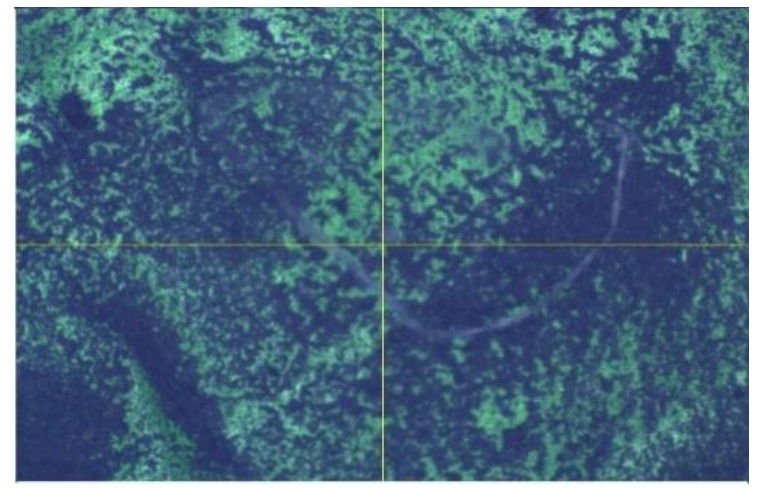

Fig. 7 A graphite powder image, magnified up to $0.001 \mathrm{~mm}$

The particles of the obtained powder (Fig. 3) have a size of $0.004 \div 0.05 \mathrm{~mm}$. In Fig. 7 the granular microstructure of the powder can be seen, which means that the particles have a suitable hexagonal shape. Due to such form of the graphite powder particles the multifunctional coating will have a smooth uniform structure without a difference in particle density and with a given degree of sedimentation, since the particles are tightly bound to each other.

The uniform homogeneous structure of the graphite powder particles contributes to the creation of an even surface of the applied layers of a multifunctional coating with a given density and thickness.

\section{Data analysis}

In order to obtain reliable results with different methods of arrangement of the electrodes, the anode process was carried out at different current densities $j$. This is possible when using anodes with different geometric dimensions, but the same cathode size.

To determine the influence of the method of arrangement of the electrodes during electrosynthesis, it is necessary to estimate the Specific energy consumption $e$. This is the energy consumption per unit mass of the product obtained [38]:

$$
e=\frac{V \times I \times t}{m}
$$

where $V$ is the voltage during electrosynthesis, $I$ is the electric current of electrosynthesis, $t$ is the time of electrosynthesis; $m$ is the mass of the obtained fine graphite powder.

The productivity of electrosynthesis $u$ is determined [39]:

$$
u=\frac{m}{t \times A}
$$

where $A$ is the area of the working surface of the anode.

According to the results of the study in Fig. 8 shows the dependence of specific energy consumption $e$ on the volume concentration $\sigma_{i}$ and nature of the electrolyte for coaxially arrangement electrodes. The current density $j$ ranges are $29 \div 51 \mathrm{~A} / \mathrm{m}^{2}$ and $12 \div 19 \mathrm{~A} / \mathrm{m}^{2}$, depending on the volume concentration $\sigma_{i}$ and nature of the electrolyte, so for graphical display, instead of the value ranges, we will use the average values of $40 \mathrm{~A} / \mathrm{m}^{2}$ and 15 $\mathrm{A} / \mathrm{m}^{2}$.

a) 


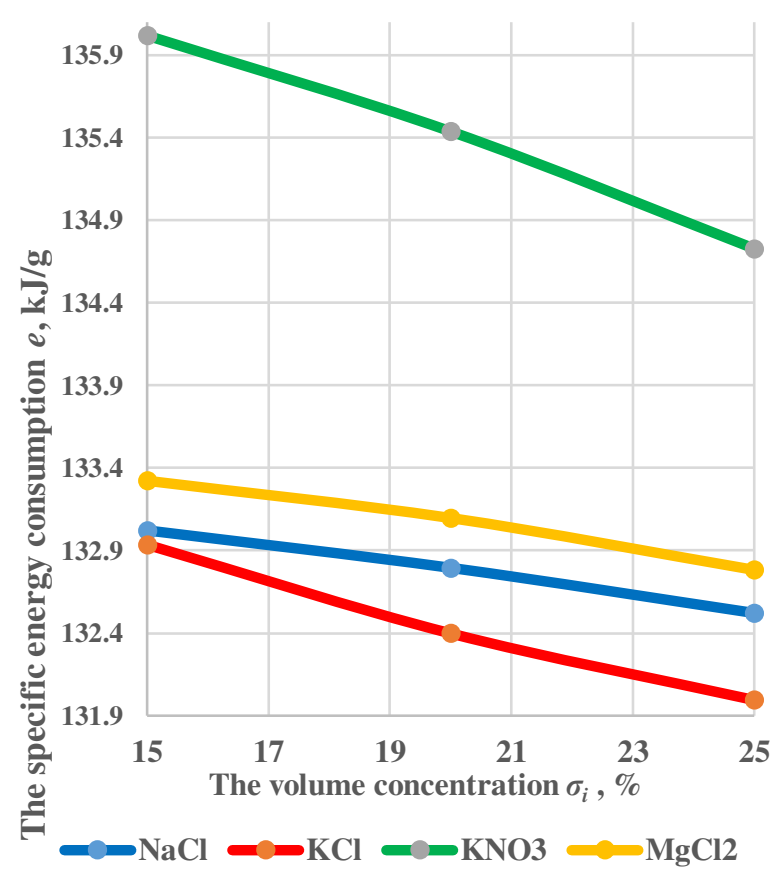

b)

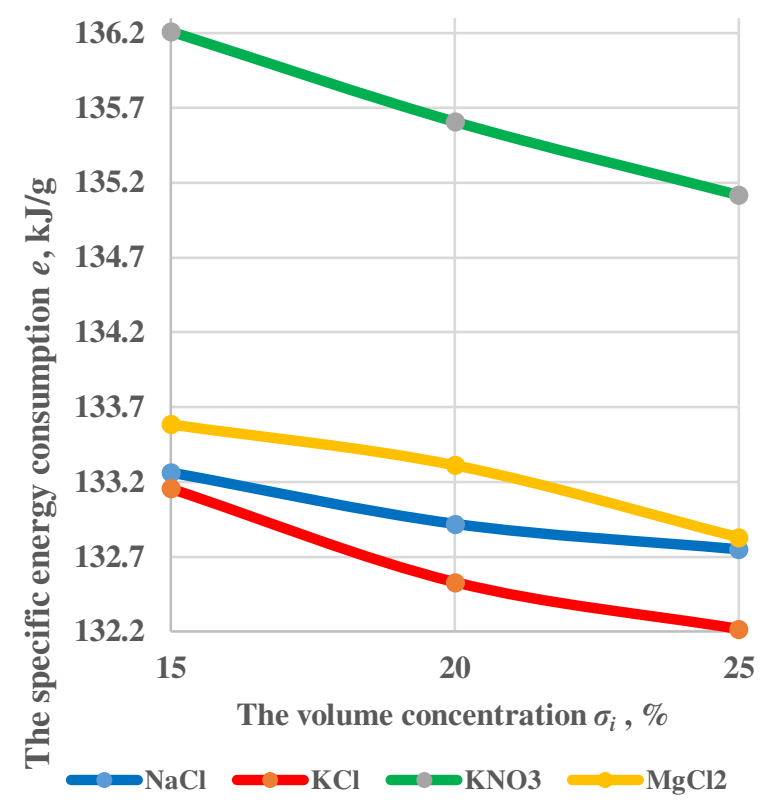

Fig. 8 Dependence of specific energy consumption $e$ on the volume concentration and composition $\sigma_{i}$ of the electrolyte for coaxially arranged electrodes: a) at an average current density $j$ of $40 \mathrm{~A} / \mathrm{m}^{2}$; b) at an average current density $j$ of $15 \mathrm{~A} / \mathrm{m}^{2}$

Despite different values of current density $j$, the specific energy consumption $e$ at the same value of direct current voltage is practically the same and varies depending on the change in the volume concentration $\sigma_{i}$ of the electrolyte. This is primarily due to the nature of the anion and cation. The lowest specific energy consumption $e$ of the electrochemical process of $132 \mathrm{~kJ} / \mathrm{g}$ was achieved at the highest current density of $51.12 \mathrm{~A} / \mathrm{m}^{2}$, using an aqueous solution of potassium chloride with a volume concentration of $25 \%$ as an electrolyte. That is, higher values of the electrical conductivity $\gamma$ of the electrolyte lead to lower specific energy consumption $e$. This is due to the high absolute mobility ions of $\mathrm{K}^{+}$and $\mathrm{Cl}^{-}$.

Fig. 9 shows the dependences of specific energy consumption $e$ on the volume concentration $\sigma_{i}$ and nature of the electrolyte for parallel arrangement electrodes. The current density $j$ ranges are $35 \div 77 \mathrm{~A} / \mathrm{m}^{2}$ and $43 \div 85 \mathrm{~A} / \mathrm{m}^{2}$, depending on the volume concentration $\sigma_{i}$ and nature of the electrolyte, so for graphical display, instead of the value ranges, we will use the average values of 56 $\mathrm{A} / \mathrm{m}^{2}$ and $64 \mathrm{~A} / \mathrm{m}^{2}$.

a)

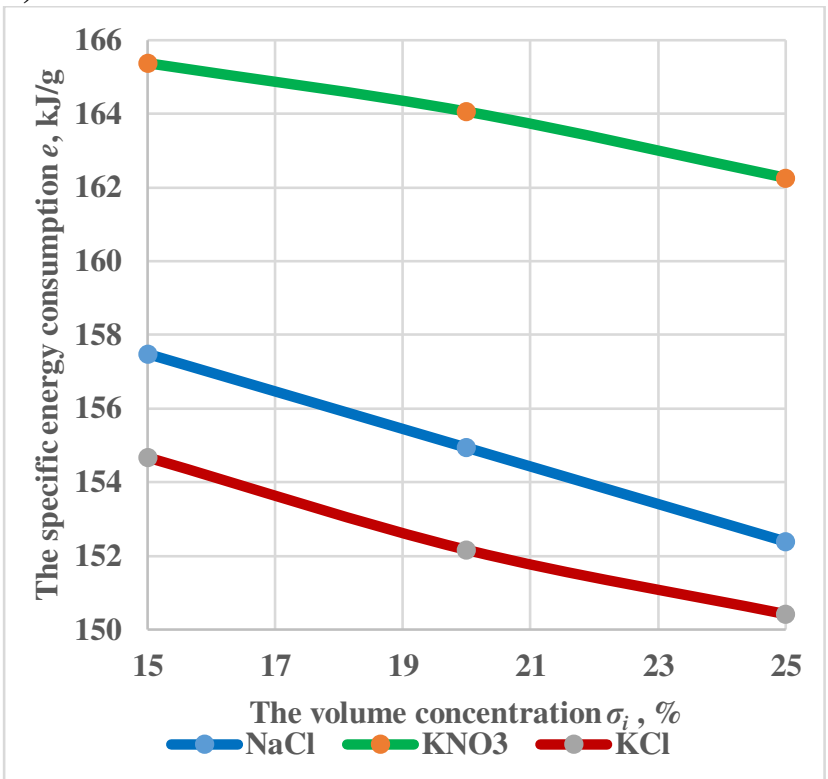

b) 


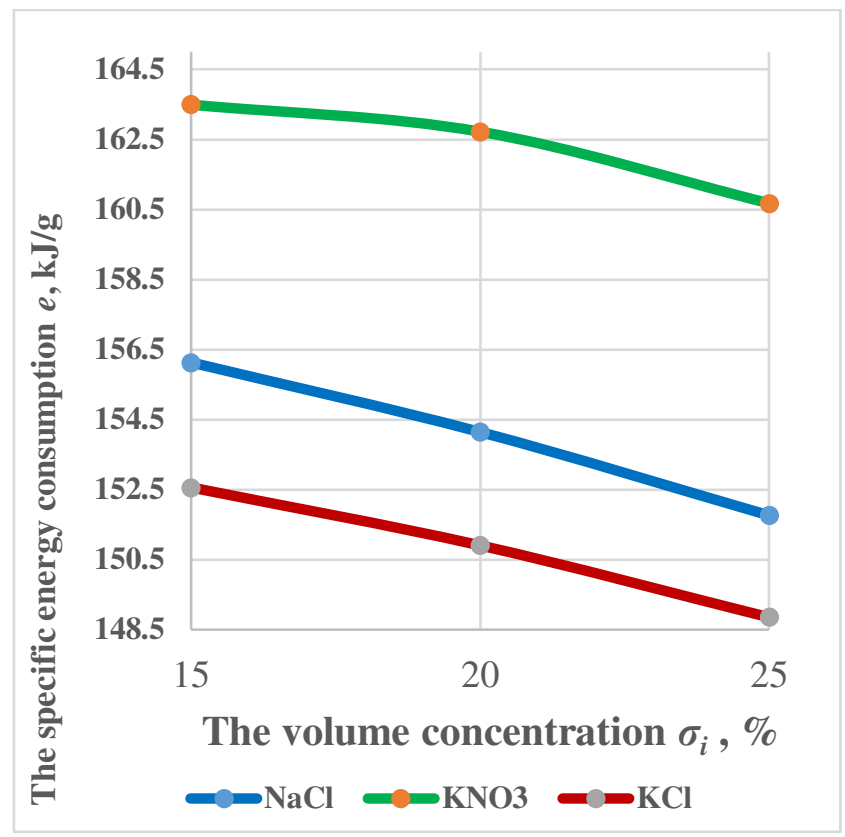

Fig. 9 Dependence of specific energy consumption $e$ on the volume concentration $\sigma_{i}$ and composition of the electrolyte for parallel electrodes: a) at an average current density $j$ of $56 \mathrm{~A} / \mathrm{m}^{2} ; \mathrm{b}$ ) at an average current density $j$

$$
\text { of } 64 \mathrm{~A} / \mathrm{m}^{2}
$$

With a parallel arrangement of electrodes, the specific energy consumption $e$ is higher. At the same time, the same pattern is visible with the dependence of specific energy consumption $e$ on the volume concentration $\sigma_{i}$ of the electrolyte and the nature of the anion and cation, with the same voltage value. The specific energy consumption $e$ has the lowest value of $149 \mathrm{~kJ} / \mathrm{g}$ when using a $25 \%$ aqueous solution of potassium chloride as an electrolyte, with the highest current density $j$ of $84.47 \mathrm{~A} / \mathrm{m}^{2}$.

Fig. 10 shows the dependence of the productivity of electrosynthesis $u$ on the volume concentration $\sigma_{i}$ and nature of the electrolyte for coaxially arranged electrodes.

a)

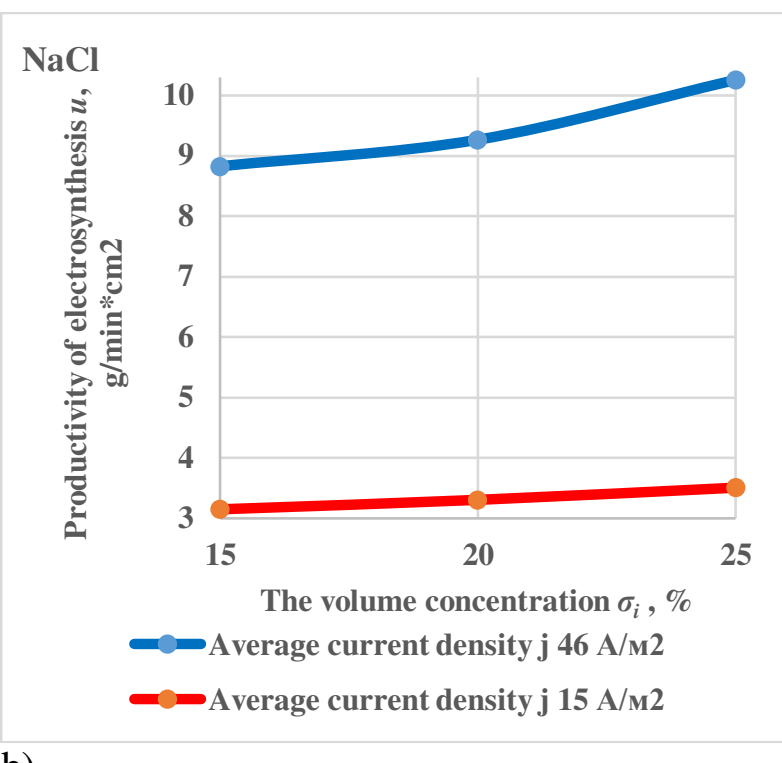

b)

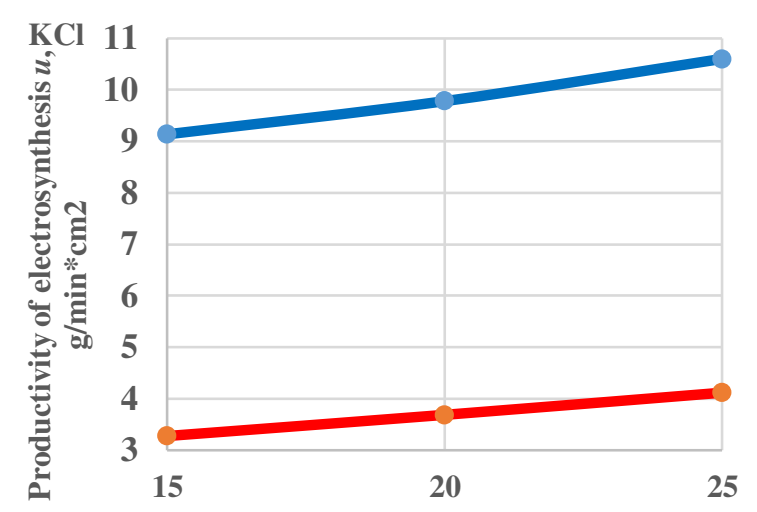

The volume concentration $\sigma_{i}, \%$

- Average current density j 48 A/M2

- Average current density j 16 A/m2

c)

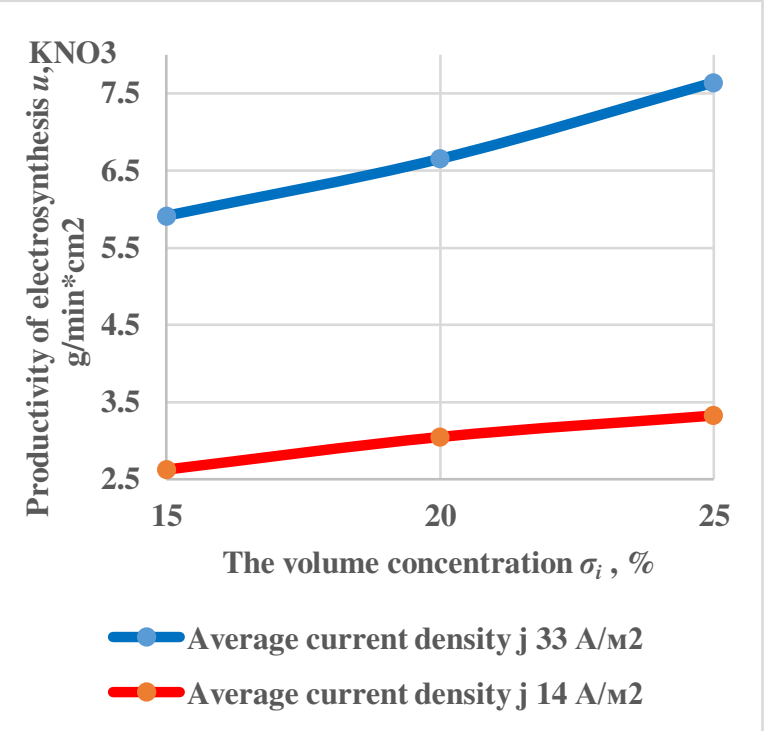

d) 


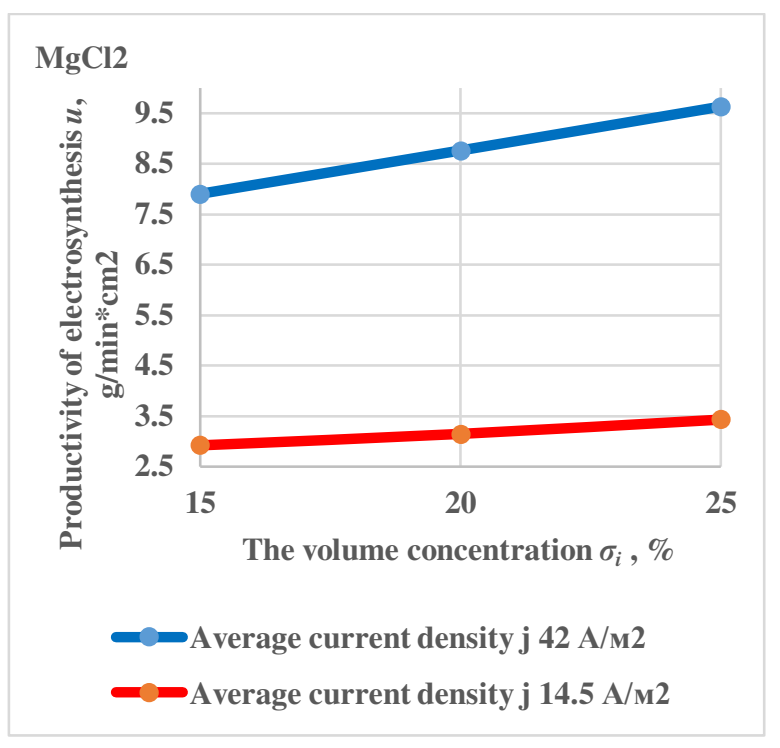

Fig. 10 Dependence of the productivity of electrosynthesis $u$ on the volume concentration $\sigma i$ and nature of the electrolyte for coaxially arranged electrodes, the electrolyte: a) sodium chloride; b) potassium chloride; c) potassium nitrate; d) magnesium chloride

Fig. 10 shows it can be concluded that a high current density $j$ increases the productivity of electrosynthesis $u$. At the same time, the dependence of productivity of electrosynthesis $u$ on the volume concentration $\sigma_{i}$ and nature of the electrolyte is also traced: with an increase in volume concentration, productivity of electrosynthesis increases. Electrolytes with higher values of the absolute mobility of ions have higher indicators of the productivity of electrosynthesis.

Fig. 11 shows the dependence productivity of electrosynthesis on the electric field at coaxial arrangement of electrodes.

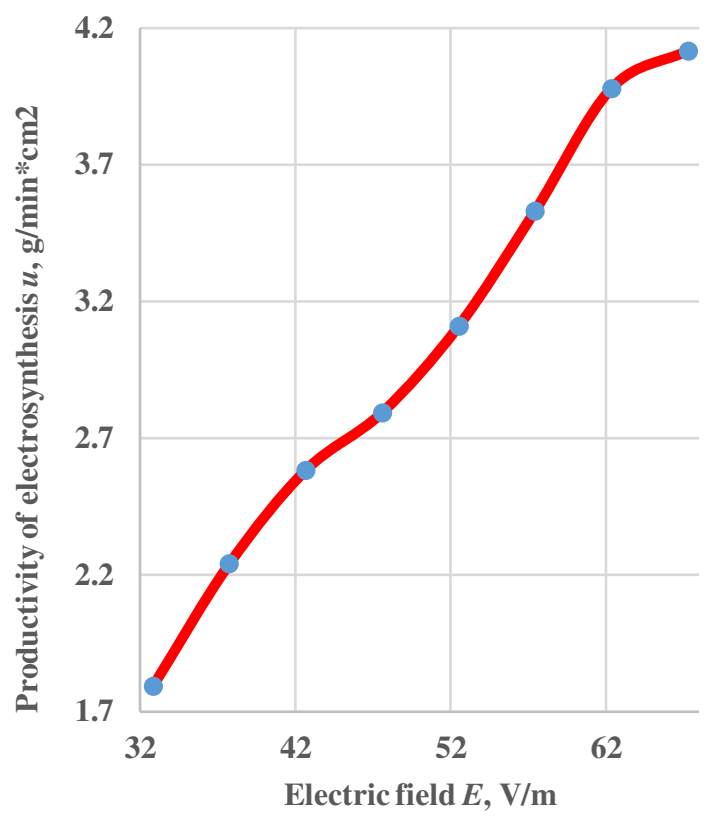

Fig. 11 Dependence of the productivity of electrosynthesis on the electric field at the coaxial arrangement of the electrodes

From the data obtained, we can conclude: with an increase in the electric field, the productivity of electrosynthesis increases. This is due to an increase in the value of ion velocity with an increase in the electric field.

\section{Conclusion}

Thus, when using a multifunctional coating as a filler, the graphite powder obtained by electrolysis from MPG-6 brand graphite with a particle size range of $0.004 \div 0.05 \mathrm{~mm}$, in comparison with mechanically crushed graphite powder, provides the following advantages:

1. Higher values of the main multifunctional coating mechanical properties (strength, rigidity and hardness), due to the high particle density of the main component;

2. Ability to reduce the thickness and number of layers of the applied coating due to the higher particle density of the main component; 3. Labor cost reduction in the production the multifunctional coating by reducing the number of main components and layers;

4. Obtaining coatings with a given density, due to a greater degree of aggregation and sedimentation of the obtained particles. 
From the point of view of the influence of the method of arrangement of electrodes during electrosynthesis on specific energy consumption and productivity of electrosynthesis:

1. Under the same conditions, the specific energy consumption has higher values with a parallel arrangement of the electrodes of $149 \div 165 \mathrm{~kJ} / \mathrm{g}$, that is, the method with a coaxial arrangement of the electrodes is more energy efficient - specific energy consumption of $132 \div 136 \mathrm{~kJ} / \mathrm{g}$;

2 . The value of specific energy consumption directly depends on the current density - the higher the anode current density, the lower the values of specific energy consumption of the electrochemical process;

3 . The particles of graphite are more actively separated from the anode at higher values of the current density, that is, with an increase in the anode current density, the number of microbubbles of the $\mathrm{O}_{2}$ gas increases, which contributes to the separation of the particles of graphite from the anode;

4. The productivity of electrosynthesis directly depends on the intensity of the electric field with increasing intensity of the electric field, the productivity of electrosynthesis also increases;

5. The productivity of electrosynthesis is higher at a high anode current density; the highest value of $10.6 \mathrm{~g} / \mathrm{min} \times \mathrm{cm}^{2}$ is achieved at a current density of $51.11 \mathrm{~A} / \mathrm{m}^{2}$;

6. In the studied range, the lowest specific energy consumption of $132 \mathrm{~kJ} / \mathrm{g}$ was obtained by an electrochemical process on an device with a coaxial arrangement of electrodes, using a $25 \%$ aqueous solution of potassium chloride at a current density of $51.12 \mathrm{~A} / \mathrm{m}^{2}$.

It is worth noting that the described technique relates to the technology of obtaining a fine powder based on graphite by electrosynthesis. The obtained fine graphite powder can be used as the main component of multifunctional coatings and materials for rocket and space, aviation and transport equipment, in the production of fire-resistant and heat-insulating materials for the chemical, nuclear industry, instrumentation and thermal power engineering. It can also have industrial applications in the production of electrical engineering, chemical equipment, electrical contacts, various rheostats, shut-off and connecting valves.

Funding The authors did not receive support from any organization for the submitted work

Author contributions Andrei V. Kupriashov: conceptualization, methodology, experimental work, investigation, and writing original draft. Ivan Y. Shestakov: resources, advisory, experimental work, review, editing and supervision.

Availability of data and material Materials are commercially available at a reasonable cost and quality result was obtained.

\section{Code availability Not applicable}

\section{Declarations}

Ethical approval All authors confirm that they follow all ethical guidelines.

Consent to participate The authors declare that they consent to participate this paper.

Consent to publish The authors declare that they consent to publish this paper and agrees with the publication.

Conflicts of interest The authors declare no competing interest.

Open Access This article is licensed under a Creative Commons Attribution 4.0 International License, which permits use, sharing, adaptation, distribution and reproduction in any medium or format, as long as you give appropriate credit to the original author(s) and the source, provide a link to the Creative Commons licence, and indicate if changes were made. The images or other third party material in this article are included in the article's Creative Commons licence, unless indicated otherwise in a credit line to the material. If material is not included in the article's Creative Commons licence and your intended use is not permitted by statutory regulation or exceeds the permitted use, you 
will need to obtain permission directly from the copyright holder. To view a copy of this licence, visit http://creativecommons.org/licenses/by/4.0/.

\section{References}

1. Makhlouf A. S. H. (2014) 6 - Protective coatings for automotive, aerospace and military applications: current prospects and future trends. Handbook of Smart Coatings for Materials Protection. 121-131. https://doi.org/10.1533/9780857096883.1.121

2. Shestakov I. Y., Kupryashov A. V., Utenkov V. D., Remizov I. A. (2020) Production of finly despersed powder from graphite by electrolysis. Siberian Journal of Science and Technology 21(4):574-580. https://doi.org/10.31772/2587-6066-2020-214-574-580.

3. Tiwary A., Kumar R., Chohan J. S. (2021) A review on characteristics of composite and advanced materials used for aerospace applications. Journal Materials today: Proceedings. https://doi.org/10.1016/j.matpr.2021.06.276.

4. Jothi V., Adesina A. Y., Kumar A. M., Al-Aqeeli N., Ram J. S. N. (2020) Influence of an anodized layer on the adhesion and surface protective performance of organic coatings on AA2024 aerospace Al alloy. Progress in Organic Coatings 138:105396. https://doi.org/10.1016/j.porgcoat.2019.10539 6 .

5. Guerriero G., Alderliesten R., Dingemans T., Benedictus R. (2011) Thermotropic liquid crystalline polymers as protective coatings for aerospace. Progress in Organic Coatings 70:245-251.

https://doi.org/10.1016/j.porgcoat.2010.09.02 7.

6. Iqbal H. M. S., Bhowmik S., Benedictus R. (2017) Performance evaluation of polybenzimidazole coating for aerospace application. Progress in Organic Coatings 105:190-199.

https://doi.org/10.1016/j.porgcoat.2017.01.00 $\underline{5}$.

7. Liu J., Li Z., Zhang L., Hou J., Lu Z., Zhang P., Wang B., Jin N. (2019) Degradation behavior and mechanism of polyurethane coating for aerospace application under atmospheric conditions in South China Sea. Progress in Organic Coatings 136:105310. https://doi.org/10.1016/j.porgcoat.2019.10531 0.

8. Bousser E., Martinu L., KlembergSapieha J. E. (2014) Solid particle erosion mechanisms of protective coatings for aerospace applications. Surface and Coatings Technology 257:165-181. https://doi.org/10.1016/j.surfcoat.2014.08.037

9. Ko M., Mai Pham L. T., Sa Y. J., Woo J., Thien Nguyen T. V., Kim J. H., Oh D., Sharma P., Ryu J., Shin T. J., Joo S. H., Kim Y. H., Jang J.-W. (2019) Unassisted solar lignin valorisation using a compartmented photoelectro-biochemical cell. Nature communications 10:5123.

10. Samal S. (2020) Effect of shape and size of filler particle on the aggregation and sedimentation behavior of the polymer composite. Powder Technology 366:43-51. https://doi.org/10.1016/j.powtec.2020.02.054.

11. Zhang W., Huo C., Hou B., Lin C., Yan X., Feng J., Yan W. (2021) Secondary particle size determining sedimentation and adsorption kinetics of titanate-based materials for ammonia nitrogen and methylene blue removal. Journal of Molecular Liquids. 117026.

https://doi.org/10.1016/j.molliq.2021.117026.

12. Fang J., Shijirbaatar A., Lin D.-H., Wang D.-J., Shen B., Sun P.-D., Zhou Z.-Q. (2017) Stability of co-existing $\mathrm{ZnO}$ and $\mathrm{TiO} 2$ nanomaterials in natural water: Aggregation and sedimentation mechanisms. Chemosphere 184:1125-1133.

https://doi.org/10.1016/j.chemosphere.2017.0 6.097.

13. Li Y., Zhang M., Hao R., Wang H., He X., Du T., Yang X., Wang Y. (2019) Influence of (photo)bromination on the transformation, aggregation and sedimentation of graphene oxide. Chemical Engineering Journal 355:487497. https://doi.org/10.1016/j.cej.2018.08.199.

14. Zhao T., Fang M., Tang Z., Zhao X., Wu F., Giesy J. P. (2019) Adsorption, aggregation and sedimentation of titanium dioxide nanoparticles and nanotubes in the presence of different sources of humic acids. Science of 
The Total Environment 692:660-668. https://doi.org/10.1016/j.scitotenv.2019.07.31 2 .

15. Ankit, Kumar V., Mishra A., Mohan S., Singh K. K., Mohan A. (2020) The effect of titanium carbide particles on microstructure and mechanical properties of copper/graphite composites prepared by flake powder metallurgy route. Journal Materials today: Proceedings 26:1140-1144. https://doi.org/10.1016/j.matpr.2020.02.228.

16. Li W., Sun J., Gao Y., Zhang Y., Ouyang J., Na N. (2021) Monitoring of electrochemical reactions on different electrode configurations by ambient mass spectrometry. TrAC Trends in Analytical Chemistry 135:116180. https://doi.org/10.1016/j.trac.2021.116180.

17. Monette D. L. (2009) 10 - Coating removal techniques in the aerospace industry. Corrosion Control in the Aerospace Industry. 225-247.

https://doi.org/10.1533/9781845695538.3.225

18. Shestakov I. Y., Kupryashov A. V. (2021) Patent application RU. 2021114124. 18.05.2021.

19. Kupryashov A.V., Shestakov I. Y. (2021) Use of carbon filler as a main component of multifunctional materials and coatings in rocket and space technology. Strengthening technologies and coatings 6(198):282-288.

https://doi.org/10.36652/1813-1336-2021-176-282-288.

20. Szeluga U., Olszowska K., Pusz S., Myalski J., Godzierz M., Kobyliukh A., Tsyntsarski B. (2021) Effect of grain fractions of crushed carbon foam on morphology and thermomechanical and tribological properties of random epoxy-carbon composites. Wear 466-467:203558.

https://doi.org/10.1016/j.wear.2020.203558.

21. Vovchenko L., Lozitsky O., Matzui L., Oliynyk V., Zagorodnii V., Skoryk M. (2020) Electromagnetic shielding properties of epoxy composites with hybrid filler nanocarbon/BaTiO3. Materials Chemistry and Physics

240:122234. https://doi.org/10.1016/j.matchemphys.2019.1 22234.
22. Song Y., Zeng L., Zheng Q. (2017) Unique liquid-to-solid transition of carbon filler filled polystyrene melts. Composites Science and Technology 147:39-44. https://doi.org/10.1016/j.compscitech.2017.05 .003.

23. McCafferty E. (2015) Surface chemistry of aqueous corrosion processes (Series: Springer Briefs in Materials). Springer, New York.

24. Pumera M. (2013) Nanomaterials for Electrochemical Sensing and Biosensing. Taylor and Francis, Abingdon.

25. Bockris J. O`M., Reddy A. K. N. (2013) Volume 1 Modern Electrochemistry. Springer, New York.

26. Zhang S., Jiang J., Wang H., Li F., Hua T., Wang W. (2021) A review of microbial electrosynthesis applied to carbon dioxide capture and conversion: The basic principles, electrode materials, and bioproducts. Journal of $\mathrm{CO} 2 \quad$ Utilization 51:101640. https://doi.org/10.1016/j.jcou.2021.101640.

27. Tang D., Zhang X., Hu S., Liu X., Ren X., Hu J., Feng Y. (2020) The reuse of red brick powder as a filler in styrene-butadiene rubber. Journal of Cleaner Production 261:120966.

https://doi.org/10.1016/j.jclepro.2020.120966.

28. Werner K., Amit S., Jurk D. R., Heinrich G. (2010) Contribution of physicochemical properties of interfaces on dispersibility, adhesion and flocculation of filler particles in rubber. Polymer 51(9):19541963.

https://doi.org/10.1016/j.polymer.2010.03.013

29. Gao M., Wang J., Zhou Y., Morshed M., Wang Z., Zhao S. (2019) Bifunctional oxygenvacancy abundant perovskite nanosheets for improving protective performance of epoxy coatings. Progress in Organic Coatings 137:105301.

https://doi.org/10.1016/j.porgcoat.2019.10530 1.

30. Jiang Y., Liang Q., Chu N., Hao W., Zhang L., Zhan G., Li D., Zeng R. J. (2020) A slurry electrode integrated with membrane electrolysis for high-performance acetate production in microbial electrosynthesis. Science of the Total Environment 741:140198. 
https://doi.org/10.1016/j.scitotenv.2020.14019

$\underline{8}$.

31. Yang G.-J. (2019) Advanced Nanomaterials and Coatings by Thermal Spray. Elsevier, Amsterdam.

32. Lin C.-T. (2019) Carbon Based Nanomaterials for Advanced Thermal and Electrochemical Energy Storage and Conversion. Elsevier, Amsterdam.

33. Buinachev S., Mashkovtsev M. A., Zhirenkina N., Aleshin D., Dankova A. (2021) A new approach for the synthesis of monodisperse zirconia powders with controlled particle size. International Journal of Hydrogen Energy 46(32):16878-16887. https://doi.org/10.1016/j.ijhydene.2021.01.13 $\underline{4}$.

34. Liu X., Yuan Y., Liu J., Liu B., Chen X., Ding J., Han X., Deng Y., Zhong C., Hu W. (2019) Utilizing solar energy to improve the oxygen evolution reaction kinetics in zinc-air battery. Nature communications 10:4767.

35. Arredondo C. H., Aguilar-Lira G., Perez-Silva I., Rodriguez J. A., Islas G., Hernandez P. (2019) Characterization and Application of Agave salmiana Cuticle as Biomembrane in Low-temperature Electrolyzer and Fuel Cells. Appl. Sci 9:4461.

36. Kostagiannakopoulou C., Tsilimigkra X., Sotiriadis G., Kostopoulos V. (2017) Synergy effect of carbon nano-fillers on the fracture toughness of structural composites. Composites Part B: Engineering 129:18-25. https://doi.org/10.1016/j.compositesb.2017.07 .012 .

37. Bian B., Shi L., Katuri K. P., Xu J., Wang P., Saikaly P. E. (2020) Efficient solarto-acetate conversion from $\mathrm{CO}_{2}$ through microbial electrosynthesis coupled with stable photoanode. Applied Energy 278:115684. https://doi.org/10.1016/j.apenergy.2020.1156 $\underline{84}$.

38. Wang X., Wei Y., Zhou H., Liu Q., Zhu L. (2021) Synthesis of graphene nanosheets by the electrical explosion of graphite powder confined in a tube. Ceramics International 47(15):21934-21942.

https://doi.org/10.1016/j.ceramint.2021.04.21 1 .

39. Mullan C. D. (2014) Supercapacitors: electrochemical properties, applications and technologies. Nova Publishers, New York. 